\title{
Influence of holding time of annealing treatment on microstructure and properties of TIG welded joint for P91 heat-resistant steel tube
}

\author{
Peng Liu ${ }^{1}$, Siyu $\mathrm{Sun}^{1}$, Shubo $\mathrm{Xu}^{1 *}$, Meiqing $\mathrm{Cao}^{2}$, Keyun Feng ${ }^{1}$ \\ ${ }^{1}$ School of Materials Science and Engineering, Shandong Jianzhu University, Jinan 250101, Shandong, P. R. China \\ ${ }^{2}$ School of Materials Science and Engineering, Shandong University of Science and Technology, \\ Qingdao 266590, P. R. China
}

Received 25 December 2017, received in revised form 27 June 2018, accepted 3 July 2018

\begin{abstract}
Optical microscope, micro-hardness tester, scanning electron microscope (SEM) and X-ray diffractometer (XRD) were applied to analyze the microstructure and properties of tungsten inert-gas arc welding (TIG) joint for P91 heat resistant steel under the different holding time of annealing treatment. The test results show that the martensite structure and retained austenite structure had a change in weld zone and heat affected zone (HAZ) with the increase of the holding time from 4 to $6 \mathrm{~h}$ with $760^{\circ} \mathrm{C}$ annealing. The microstructure in the weld zone shows the finer characteristic. The hardness in all regions tends to decrease after the annealing treatment, and the hardness is about 200-240 HV. However, the hardness in the weld zone is about 200-270 HV. The highest hardness in the weld zone and HAZ was observed when the holding time was $6 \mathrm{~h}$, and some carbide was dissolved partially with the increase of the holding time. Moreover, when the holding time was $6 \mathrm{~h}$ with $760^{\circ} \mathrm{C}$ annealing, some small dispersed precipitated phases were distributed in the substrate. Thus, the microstructure and properties of TIG welded joint used for holding time $6 \mathrm{~h}$ are better than those for holding time 4 and $5 \mathrm{~h}$.

K e y w or d s: P91 heat-resistant steel, annealing, holding time, microstructure, phase constitution
\end{abstract}

\section{Introduction}

P91 heat-resistant steel is a kind of modified martensite alloys steel (9Cr-1Mo). The microstructure is composed of martensite and ferrite, which has good structure stability, high temperature enduring strength and high temperature creep strength [1-3]. Up to now, P91 steel has been most widely used in main steam pipeline, the superheater and reheater of plant boiler, the heat exchanger of nuclear, boiler tube of oil cracking equipment [4-6].

However, there were some welding quality problems in the actual production of P91 heat-resistant steel, such as weld crack, slag inclusion and lack of penetration in the root of weld $[7,8]$. At present, many types of research on the welding technology, post-weld heat treatment, microstructure and prop- erties for P91 heat resistant steel have been reported [9-11]. However, these researches mainly focused on the selection of the welding process and heat treatment methods $[12,13]$. Carefully combined with the installation of supercritical units, the research on the relationship among the heat treatment temperature, holding time and structural properties and the microstructural changes of the welded joints for P91 heat resistant steel has been rarely reported [14, 15], especially in aspect of reducing the holding time effectively to ensure the proper microstructure and properties of the welded joint at the same time. Therefore, when the microstructure and properties of the welded joint are ensured, the appropriate decrease in the holding time can significantly enhance the welding efficiency to save the energy, consumption materials and production costs. 
Peng Liu et al. / Kovove Mater. 562018 245-252

Table 1. The chemical composition of P91 heat-resistant steel tube and ER90S-B9 filler wire (wt.\%)

\begin{tabular}{ccccccccccccc}
\hline \multicolumn{10}{c}{ P91 heat-resistant steel tube } \\
\hline $\mathrm{C}$ & $\mathrm{Si}$ & $\mathrm{Mn}$ & $\mathrm{S}$ & $\mathrm{P}$ & $\mathrm{Cr}$ & $\mathrm{Mo}$ & $\mathrm{Ni}$ & $\mathrm{Al}$ & $\mathrm{V}$ & $\mathrm{Nb}$ & $\mathrm{N}$ \\
\hline 0.09 & 0.20 & 0.40 & 0.01 & 0.20 & 9.60 & 1.05 & 0.40 & 0.35 & 0.25 & 0.10 & 0.07 \\
\hline \multicolumn{10}{c}{} & & \multicolumn{10}{c}{ ER90S-B9 filler wire } & & & & \\
\hline $\mathrm{C}$ & $\mathrm{Mn}$ & $\mathrm{Si}$ & $\mathrm{P}$ & $\mathrm{S}$ & $\mathrm{Cr}$ & $\mathrm{Mo}$ & & $\mathrm{V}$ \\
\hline $0.07-0.13$ & 1.25 & 0.3 & 0.01 & 0.01 & $8.0-10.0$ & $0.8-1.1$ & $0.15-0.25$ \\
\hline
\end{tabular}

Table 2. The welding parameters of TIG welding for P91 heat-resistant steel tube

\begin{tabular}{ccccc}
\hline Welding layer & The diameter of filler wire (mm) & Welding current (A) & Arc voltage (V) & Welding speed (mm s $\left.{ }^{-1}\right)$ \\
\hline $1-3$ & 2.4 & $80-110$ & $10-14$ & $15-20$ \\
\hline
\end{tabular}

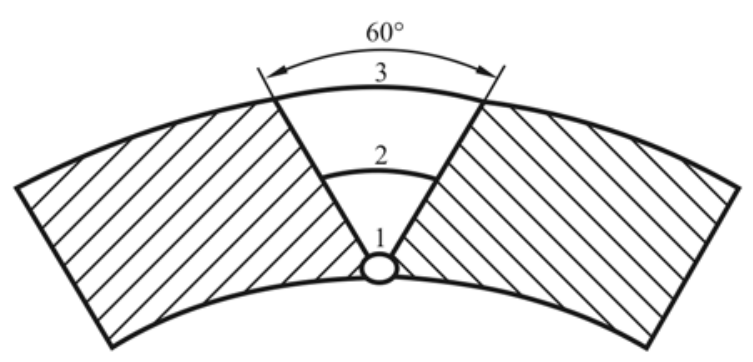

Fig. 1. The geometry of the weld configuration.

In this paper, P91 heat-resistant steel pipe was welded by tungsten inert-gas arc welding (TIG), and the appropriate annealing temperature was selected. This article mainly analyzes the change characteristics in the aspect of the microstructure and properties of TIG welded joint for P91 heat resistant steel under different holding time, especially in less than the common holding time. Some influencing factors for the change of microstructure and properties of joints were also studied and analyzed under different annealing conditions. This provides an important research basis for optimizing the heat treatment process of P91 heat-resistant steel.

\section{Experimental}

The outer diameter of P91 heat-resistant steel tube is $45 \mathrm{~mm}$, and the wall thickness is $5 \mathrm{~mm}$. TIG welding method was used to join the steel tube. The grade of the base material is $10 \mathrm{Cr} 9 \mathrm{Mo} 1 \mathrm{VNb}$. The groove is required in the process of TIG welding, and the groove details are shown in Fig. 1. The chemical composition and mechanical properties of P91 heat-resistant steel

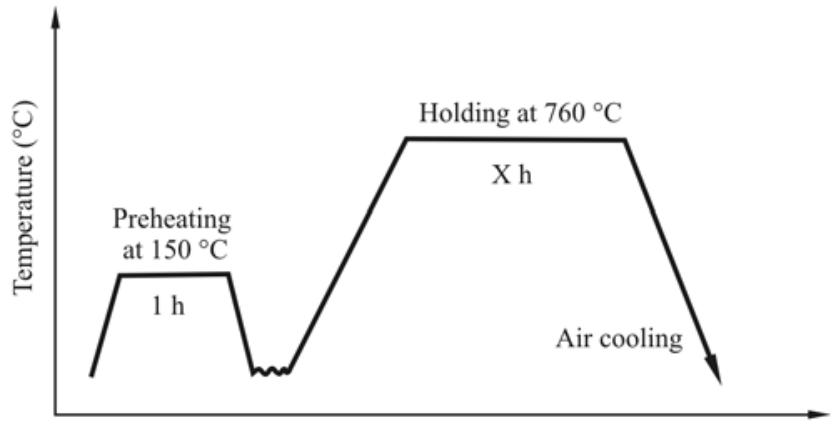

Fig. 2. The process curve of annealing treatment.

tube are shown in Table 1. During the TIG welding, the ER90S-B9 filler wire was used, and the chemical composition is shown in Table 2.

Oil, paint, scale, rust, burrs near the groove at the range of $15-20 \mathrm{~mm}$ must be cleaned up before TIG welding. The preheat temperature before welding was $150{ }^{\circ} \mathrm{C}$, and the interlayer temperature should be maintained at the range of $200-250^{\circ} \mathrm{C}$. The specific welding parameters are showed in Table 2. The annealing treatment for TIG welded joints was performed. The annealing temperature was $760 \pm 10^{\circ} \mathrm{C}$, and the holding time was 4,5 and $6 \mathrm{~h}$, respectively. Then, these specimens were direct air cooled to room temperature, and the process curve of the heat treatment is shown in Fig. 2.

Microstructure, hardness and phase constituents before and after annealing treatment for TIG welded joints were observed and analyzed using a metallographic optical microscope, micro-hardness tester, scanning electron microscope (SEM) and X-ray diffractometer (XRD). Ratio of eroding solution is $5 \mathrm{~g}$ $\mathrm{FeCl}_{3}+50 \mathrm{ml} \mathrm{HCl}+100 \mathrm{ml} \mathrm{H}_{2} \mathrm{O}$. The test equipment 

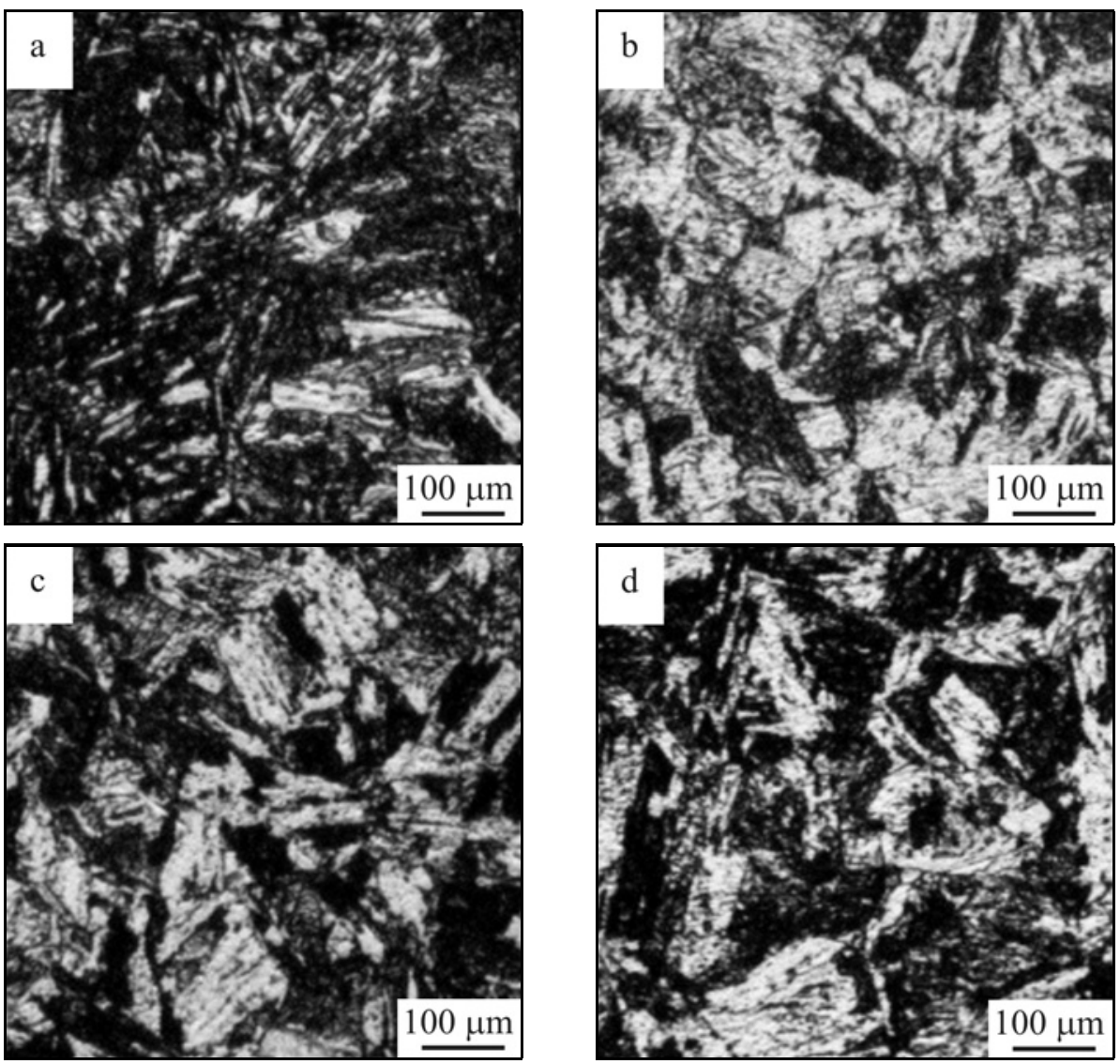

Fig. 3. Microstructure in HAZ under different holding time: (a) unannealed, (b) $760{ }^{\circ} \mathrm{C}+4 \mathrm{~h}$, (c) $760{ }^{\circ} \mathrm{C}+5 \mathrm{~h}$, and $(\mathrm{d})$ $760^{\circ} \mathrm{C}+6 \mathrm{~h}$.

used is as follows: Horizontal metallurgical microscope of Nikon Epiphot 300U/200, Scanning electron microscope of JSM-6380LA and X-ray diffractometer of $\mathrm{D} / \max -\mathrm{rc}$.

\section{Results and analysis}

\subsection{Influence of holding time on microstructure in $\mathrm{HAZ}$}

In the HAZ of the TIG welding joint for P91 heatresistant steel before the annealing treatment, the microstructure, which is composed of initial phase $\alpha$ and acicular crystal phase $\beta$, has an obvious martensitic lath bundle, while it has a coarse banded structure. After the annealing process of $760^{\circ} \mathrm{C}+4 \mathrm{~h}$, the microstructure of the HAZ showed the typical plate martensite structure (see Fig. 3b). However, the proportion of retained austenite is gradually decreased. After the $760^{\circ} \mathrm{C}+5 \mathrm{~h}$ annealing treatment, the microstructure of the HAZ also shows the plate martensite structure (see Fig. 3c). At this time, the microstructure in the HAZ is finer than the process of $760{ }^{\circ} \mathrm{C}+4 \mathrm{~h}$ annealing treatment. When the $760{ }^{\circ} \mathrm{C}+$
$6 \mathrm{~h}$ annealing process was used, the microstructure in the HAZ was composed of the plate martensite structures (see Fig. 3d). Using this process, the microstructure obtains a bigger phase proportion, a smaller grain size and a less preheat temperature retained austenite structure.

According to the above analysis, it is clear that the microstructure in HAZ experienced the annealing treatment had a change obviously from the broadband and lath martensite to the plate martensite, and the retained austenite proportion also decreased. The reason of structure transformation from lath martensite (unannealed) to plate martensite (annealing) in $\mathrm{HAZ}$ is because of the high annealing temperature and the low CRSS (Critical Resolved Shear Stress) of slippage [16]. Therefore, it was easier to slipping than twinning, and it had lots of dislocations in the substrate. Meanwhile, because of the high temperature and lower strength of the austenite and martensite, the phase transforming stress was released through the way of slippage, which is helpful to obtain the lath martensite. When the transformation temperature was decreased, the twinning structure was formed and induced the lath martensite to transform into plate martensite [17]. 

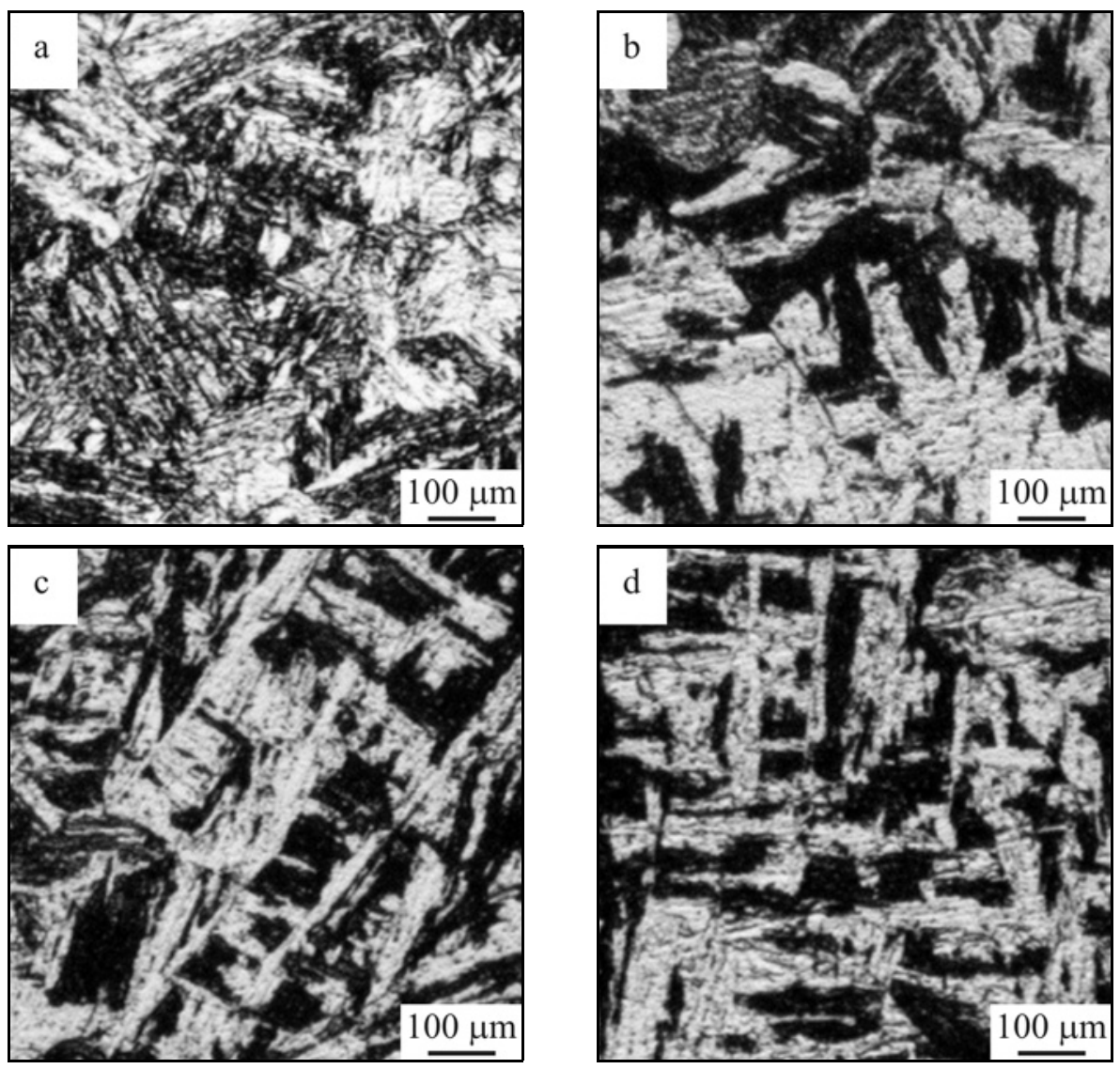

Fig. 4. Microstructure in weld zone under different holding time: (a) unannealed, (b) $760{ }^{\circ} \mathrm{C}+4 \mathrm{~h}$, (c) $760{ }^{\circ} \mathrm{C}+5 \mathrm{~h}$, and (d) $760{ }^{\circ} \mathrm{C}+6 \mathrm{~h}$.

\subsection{Influence of holding time on microstructure in the weld zone}

The microstructure in the weld zone before the annealing treatment showed typical lath martensite (see Fig. 4a). After the $760^{\circ} \mathrm{C}+4 \mathrm{~h}$ annealing process, the microstructure in the weld zone showed the acicular martensite (see Fig. 4b). The retained austenite with some ferrite existed around martensite. However, when an annealing process with $760^{\circ} \mathrm{C}+5 \mathrm{~h}$ was used, the microstructure in the weld zone shows the plate martensite (see Fig. 4c). Also, the crystal size of retained austenite is bigger than the one at $760^{\circ} \mathrm{C}+4 \mathrm{~h}$ annealing treatment. After an annealing process with $760^{\circ} \mathrm{C}+6 \mathrm{~h}$, the microstructure in the weld zone also shows the plate martensite (see Fig. 4d). Compared with $760^{\circ} \mathrm{C}+5 \mathrm{~h}$ annealing treatment, the fine plate martensite is obtained.

The above analysis indicates that the microstructure in the weld zone under the different annealing experienced a change. Microstructures in weld zone produced a transformation from lath martensite to acicular martensite and plate martensite. The holding time played an important role in influencing the microstructural transformation. As a result, the microstructure in the weld zone transformed from lath martensite to acicular martensite under holding temperature of $4 \mathrm{~h}$. The microstructure in the weld zone transformed further from lath martensite to plate martensite under holding temperature $5 \mathrm{~h}$, and the crystal size of retained austenite became coarse. Then, the microstructure under holding temperature $6 \mathrm{~h}$ also showed the plate martensite, which was finer than the one under holding temperature of $5 \mathrm{~h}$.

\subsection{Influence of holding time on hardness distribution for TIG welded joint}

According to the above microstructural analysis, it is shown that the microstructure produced a change obviously under different holding time. Therefore, it is possible to reflect the relation between the microstructural changes and the holding time through analyzing hardness distribution. The hardness distribution under different annealing process for TIG welded joint of P91 heat-resistant steel is shown in Fig. 5.

The test results show that the descending of hardness distribution is similar between unannealed state and holding time $4 \mathrm{~h}$. The hardness increased from base metal to the weld zone and reached its peak 


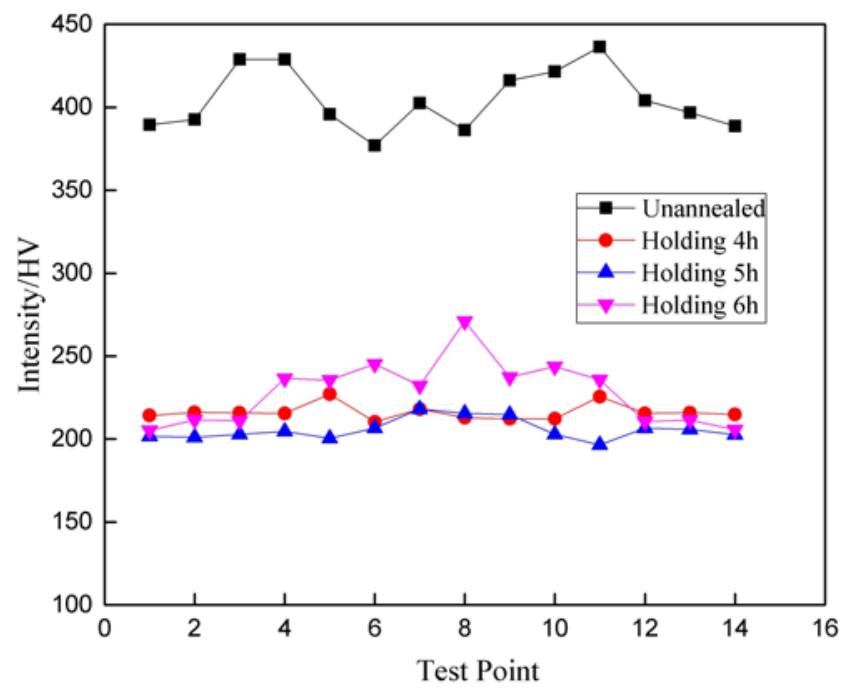

Fig. 5. The curve of hardness distribution for TIG welded joint.

in HAZ. While in the weld zone, the distribution of hardness is smooth. However, the descending of hard- ness distribution is similar between the holding time of 5 and $6 \mathrm{~h}$. For the unannealed joint, it has a significant variation in hardness distribution. The highest hardness in HAZ reaches to $430 \mathrm{HV}$, and the highest hardness in the weld zone also reaches to 400 $\mathrm{HV}$. The hardness distribution of joint after annealing has leveled off, and the hardness of the joint by annealing decreased considerably. The range of hardness is $200-240 \mathrm{HV}$ in $\mathrm{HAZ}$, and $200-270 \mathrm{HV}$ in the weld zone. When the $760^{\circ} \mathrm{C}+6 \mathrm{~h}$ annealing was used, the hardness in the weld zone was higher than the one of other holding time. This reason is according to the microstructural transition and grain refinement [18]. In our researches, after the $6 \mathrm{~h}$ annealing, the microstructure shows the relatively fine character, and some second phase's particle could present the disperse distribution to induce an obvious pinning effect.

Combining with analysis of microstructure indicated that the hardness in HAZ and weld zone considerably changed by annealing. The hardness distribution leveled off owing to microstructure transformed from lath martensite to plate or acicular martensite. However, a few of ferrite was found in HAZ and weld
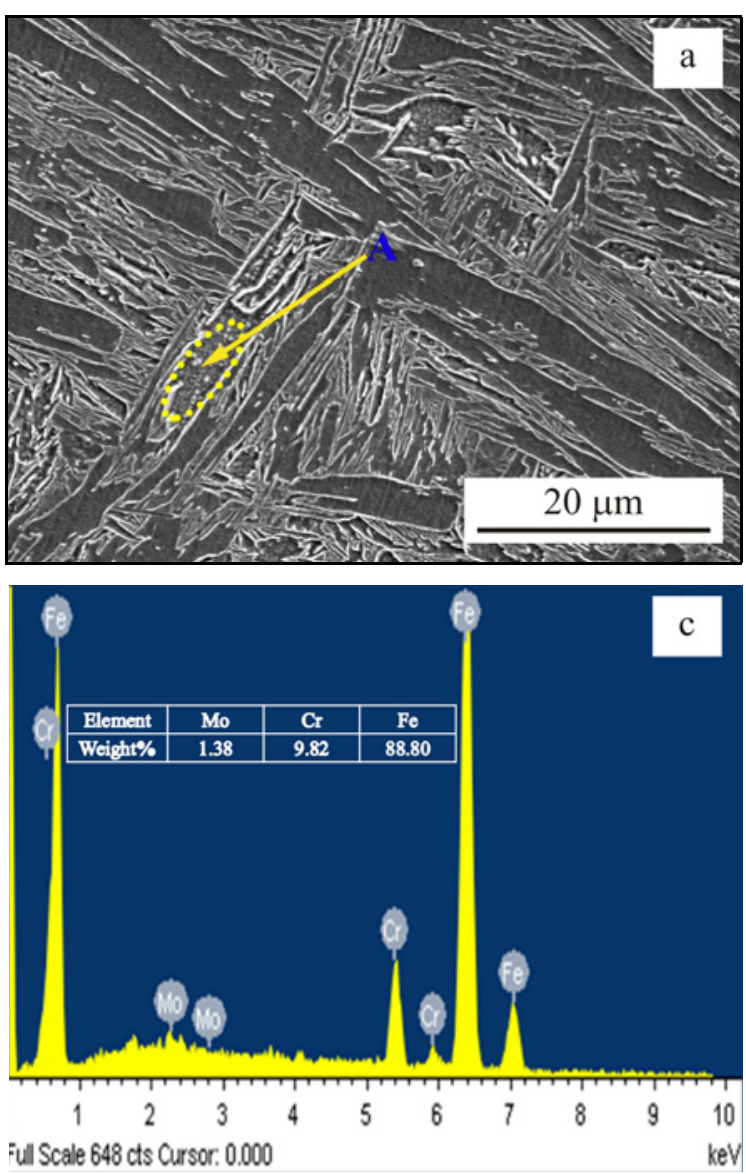
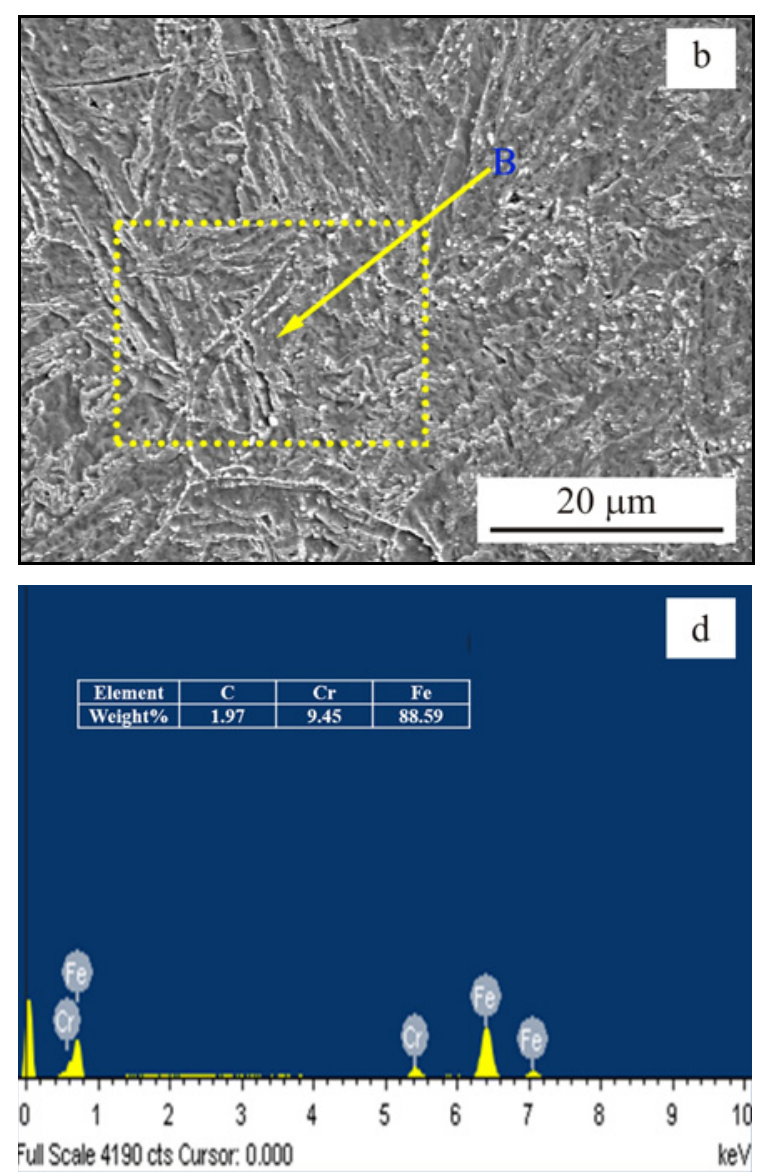

Fig. 6. SEM morphology and EDS analysis in weld zone under different holding time: (a) SEM morphology of joint unannealed, (b) SEM morphology under holding $6 \mathrm{~h}$, (c) EDS result in A region, and (d) EDS result in B region. 

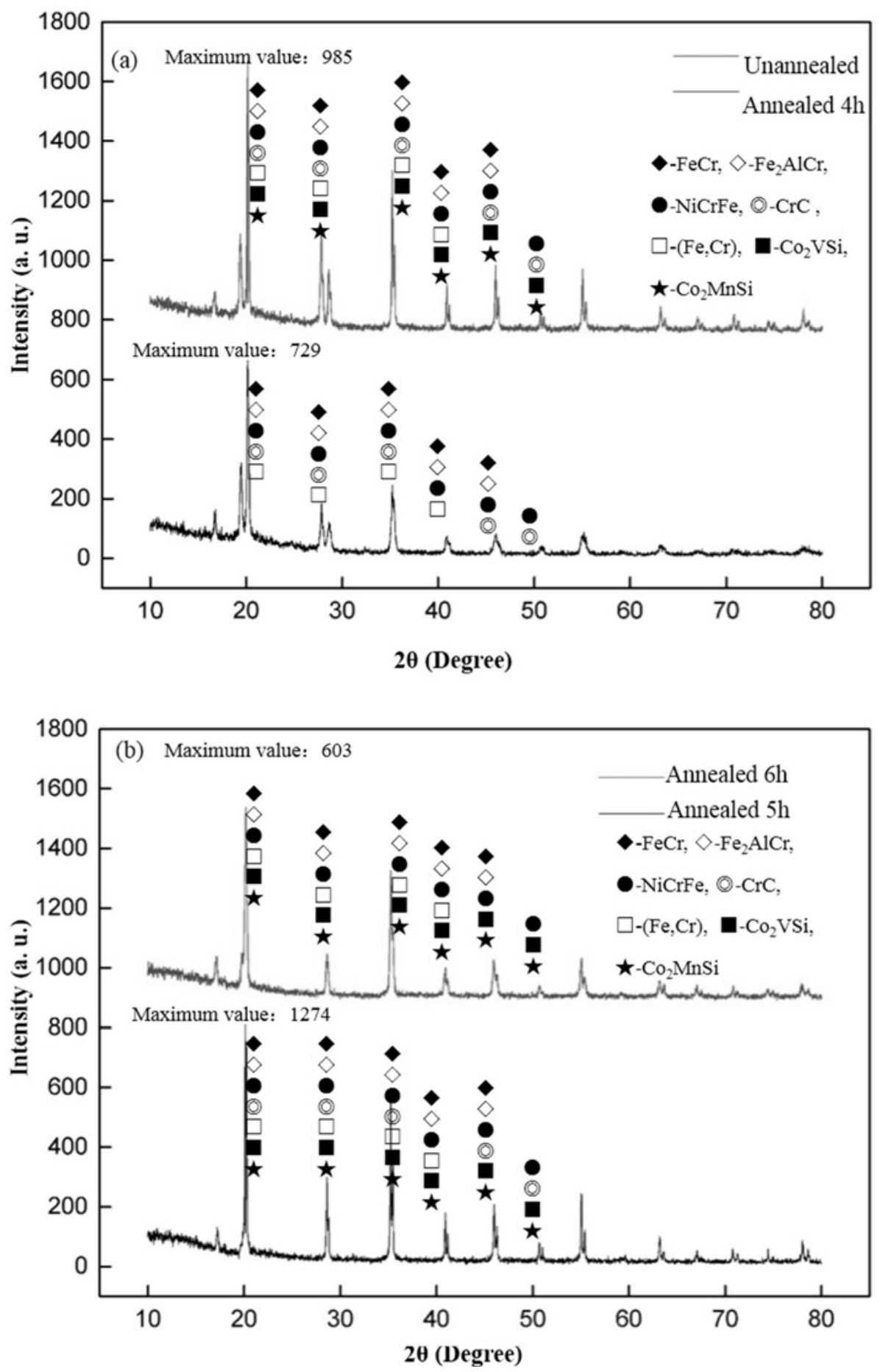

Fig. 7. XRD curve of TIG welded joint under different annealing treatment: (a) unannealed and annealed $4 \mathrm{~h}$, and (b) Annealed $5 \mathrm{~h}$ and annealed $6 \mathrm{~h}$.

zone. A mixed microstructure consisting of martensite with some ferrite was formed possibly in some areas, and the hardness was also higher than the one of single acicular martensite, and lower than the one of lath martensite. Therefore, the holding time has a great influence on microstructural transition and hardness distribution.

\subsection{Influence of holding time on phase constitution}

The test results of SEM and EDS before and after the annealing for TIG welded joint are shown in Fig. 6. The precipitated phases are mainly distributed on grain boundaries and martensitic lath boundaries 
in the form of particle or rod before the annealing (see Fig. 6a). However, some precipitated phases gathered in A region of Fig. 6a. This may be caused by containing a large amount of element $\mathrm{Cr}$, which these precipitated phases were extremely easy to grow up around the particles rich in Cr. According to Fig. 6c, the chemical composition of A region is $\mathrm{Fe}, \mathrm{Cr}, \mathrm{Mo}$, and $\mathrm{C}$.

These fine precipitated phases are mainly distributed in grain boundaries and martensitic boundaries and interior in the form of particle or rod (see Fig. 6b). This limits the further growth of martensite while holding temperature by pinning crystal boundary effectively. Thus, the microstructure in the weld zone shows fine characteristic. According to Fig. 6d, these precipitated phases are mainly composed of elements $\mathrm{Fe}$ and $\mathrm{Cr}$.

The XRD results are shown in Fig. 7. The precipitated phases before the annealing in weld zone are mainly composed of $\mathrm{MoC}, \mathrm{Co}_{2} \mathrm{C}, \mathrm{CrC}, \mathrm{Fe}-\mathrm{Cr}$, $\mathrm{Fe}_{2} \mathrm{AlCr},(\mathrm{Fe}, \mathrm{Cr}$ ), $\mathrm{Cr}$, etc., and the heavy precipitation of the second phase makes the hardness of the weld significantly improved.

When the holding time is $4 \mathrm{~h}$, some second phases as $\mathrm{Co}_{2} \mathrm{VSi}, \mathrm{Co}_{2} \mathrm{MnSi}$ continued to precipitate. However, the hardness in the weld zone has difference before annealing and after annealing. This is owing to reducing of dislocation density and microstructural transformation. With the extending of holding time, partial carbides as $\mathrm{CrC}$ are dissolved. This can decrease hardness by reducing dislocation pinning force. In the process of holding time $6 \mathrm{~h}$, the small second phase was dispersed and distributed in grain boundaries and martensitic lath boundaries and interior. This limits the further growth of martensite during holding temperature. Thus, the fine microstructure in the weld zone is obtained. The microstructure and properties in weld zone which used the holding time $6 \mathrm{~h}$ are better than the ones of holding time $4 \mathrm{~h}$ and $5 \mathrm{~h}$ by the fine grain reinforcing.

\section{Conclusions}

From the novel studies including microstructure, hardness, phase transition on the effect of different holding time of annealing treatment compared with the previous some studies about the annealing treatment of TIG welded joint for P91 steel, especially holding time $4 \mathrm{~h}$ and $5 \mathrm{~h}$, the following concluding remarks can be drawn:

1. The microstructure in HAZ of TIG welded joint under different holding time shows lath martensite structure. With the increase of holding time, the fine lath martensite is obtained, and the proportion of retained austenite is also gradually decreased. However, the microstructure in the weld zone transformed from acicular martensite to plate martensite, and the grain size of retained austenite turned into the coarse austenite.

2. The hardness distribution of TIG welded joint before the annealing has a significant variation. The highest hardness in HAZ reaches $430 \mathrm{HV}$, and the highest hardness in the weld zone also reaches $400 \mathrm{HV}$. The hardness distribution of TIG welded joint after the annealing has leveled off. The range of hardness is $200-240 \mathrm{HV}$ in $\mathrm{HAZ}$, and $200-270 \mathrm{HV}$ in the weld zone. When the $760^{\circ} \mathrm{C}+6 \mathrm{~h}$ was used, the hardness in the weld zone is higher than for other holding time.

3 . The precipitated phase is mainly distributed in grain boundaries and martensitic boundaries and interior in the form of particle or rod after annealing. Partial carbides as $\mathrm{CrC}$ are dissolved when the holding time is $5 \mathrm{~h}$. In the process of holding time $6 \mathrm{~h}$, some fine dispersed precipitated phases are well distributed in the substrate. This limits the further growth of martensite while holding temperature by pinning the crystal boundary effectively, and the fine microstructure in the weld zone is obtained. The microstructure and properties of TIG welded joint which used the holding time $6 \mathrm{~h}$ are better than the ones for holding time 4 and $5 \mathrm{~h}$.

\section{Acknowledgements}

This research was financially supported by the Shandong Provincial Natural Science Foundation, China (Grant No. ZR2016JL017) and the Key Research Development Program of Shandong Province, China (Grant No. 2017GGX30128).

\section{References}

[1] Williams, J. A., Parker, J. D.: Mater. Sci. Eng. A, 4, 1995, p. 242. doi:10.1016/0921-5093(95)09778-3

[2] Pandey, C., Mohan, M., Kumar, P., Saini, N.: J. Manuf. Proc., 31, 2018, p. 247. doi:10.1016/i.jmapro.2017.11.020

[3] Kukla, D., Kowalewski, Z., Grzywna, P., Kubiak, K.: Kovove Mater., 52, 2014, p. 269. doi:10.4149/km_2014_5_269

[4] Paddea, S., Francis, J. A., Paradowska, A. M., Bouchard, P. J., Shibli, I. A.: Mater. Sci. Eng. A, 534, 2012, p. 663. doi:10.1016/j.msea.2011.12.024

[5] Kamal, H. D., Vishvesh, J. B.: J. Manuf. Proc., 17, 2015, p. 48. doi:10.1016/j.jmapro.2014.10.004

[6] Divya, M., Das, C. R., Albert, S. K., Goyal, S., Ganesh, P., Kaul, R., Swaminathan, J., Murty, B. S., Kukreja, L. M., Bhaduri, A. K.: Mater. Sci. Eng. A, 613, 2014, p. 148. doi:10.1016/j.msea.2014.06.089

[7] Arivazhagan, B., Sundaresan, S., Kamaraj, M. J.: Mater. Proc. Tech., 209, 2009, p. 5245. doi:10.1016/j.jmatprotec.2009.02.006

[8] Arivazhagan, B., Kamaraj, M. J.: Manuf. Proc., 15, 2013, p. 542. doi:10.1016/j.jmapro.2013.07.001 
[9] Pandey, C., Mahapatra, M. M., Kumar, P., Saini, N.: Mater. Sci. Eng. A, 712, 2018, p. 720. doi:10.1016/j.msea.2017.12.039

[10] Zhang, H., Long, B., Dai, Y. J.: Nuclear Mater., 377, 2008, p. 122. doi:10.1016/j.jnucmat.2008.02.037

[11] Pandey, C., Giri, A., Mahapatra, M. M., Kumar, P.: Metals Mater. Inter., 23, 2017, p. 148. doi:10.1007/s12540-017-6394-5

[12] Ahmed, S., Fred, S.: Inter. J. Pressure Vessels Piping, 84, 2007, p. 114. doi:10.1016/j.ijpvp.2006.11.002

[13] Pandey, C., Mahapatra, M. M., Kumar, P., Saini, N.: Mater. Sci. Eng. A, 685, 2017, p. 39. doi:10.1016/j.msea.2016.12.079

[14] Gong, Y., Yang, Z. G., Yang, F. Y.: J. Mater. Eng. Perf., 21, 2012, p. 1313.

doi:10.1007/s11665-011-0048-4
[15] Pandey, C., Mahapatra, M. M., Kumar, P., Saini, N., Srivastava, A.: J. Manuf. Proc., 28, 2017, p. 220. doi:10.1016/j.jmapro.2017.06.009

[16] Pandey, C., Mahapatra, M. M., Kumar, P., Giri, A.: Metals Mater. Inter., 23, 2017, p. 900. doi:10.1007/s12540-017-6850-2

[17] Zhou, X. S., Liu, Y. C., Qiao, Z. X., Guo, Q. Y., Liu, C. X., Yu, L. M., Li, H. J.: Fusion Eng. Des., 125, 2017, p. 354. doi:10.1016/i.fusengdes.2017.05.095

[18] Pandey, C., Mahapatra, M. M.: J. Mater. Eng. Performance, 25, 2016, p. 2195. doi:10.1007/s11665-016-2064-x 